\title{
The Library on the Air
}

\section{University of Utah}

$\mathrm{T}$ HE LIBRARY of the University of Utah was given the privilege of offering one of the nine thirty-minute programs presented by the university on Radio Station KSL during the school year of 1945-46. The library program was presented Mar. 15. 1946 .

The program was scheduled from 10:00 to $10: 30$ in the evening. This is a choice commercial time; therefore, it was impressed upon all of the participants in the university programs that the offerings would have to be unusually good to warrant retaining this critical one-half hour.

Work was not begun on the program seriously until early in January. At this time the librarian, with the assistance of the staff members, outlined two possible programs. One was a quiz program. After careful consideration, however, the librarian abandoned the idea of a quiz program.

Since the purpose of the broadcast was to tell the people of the state of Utah and the intermountain territory things they should know about the work done in the university library, it seemed completely impossible that listeners to a quiz program could know anything about the book stacks, the services rendered, and such items. They would be unable to answer the questions asked. It is, of course, obvious that half the fun of listening to a quiz type of program is the fun the listeners get in rating themselves. The listener is delighted to find that occasionally he knows the answer sooner than the expert or the man in the street. Therefore, the quiz type of program was out when it was apparent selfrating would not be possible.
The next type of program, actually outlined in some detail, was one in which the library presented various library staff members, who then told the listeners of their daily work. The script for this program was tried out on an extension class of the university with some favorable comment. However, the Radio Guild of the university and the director of the University Radio Series both stated that they felt this script was chloroform on the air.

At the suggestion of the director of the series and the Radio Guild members, the librarian then outlined a tour through the university library with an imaginary group of freshmen asking questions and receiving answers about things which impress visitors. Much of the material was the same as that used in the rejected script. The trial audience liked the new treatment much better.

The thing which made the radio program really successful was the fact that after the librarian had outlined these two scripts he turned them over to the Radio Guild of the university for its members to do with as they pleased. Talented youngsters who had been studying radio from three to four months, and some of them for years, then wrote the script in the form of a radio fantasy. Some of the things these young writers did sound frankly amateurish. For instance, they went back to pioneer days and had an argument between a husband and wife re-enacted as to whether or not there was room in a covered wagon for books.

Several of the writers called on the librarian during this time to get additional 
information and criticism. The librarian was apprehensive when the young writers announced they were going to give the library a voice and have the building talk to a drowsy student! But the net effect was surprisingly good.

The Radio Guild provided actors as well as writers. It also provided the incidental music and other sound effects, which amounted to no small task in a one-half hour program. The program finally went through without difficulty. It ran twelve seconds longer than the program director had planned, thus causing the omission of the names of the actors.

The reaction of the university faculty to the program was good. This was an extra compliment as the program was not planned for them. The radio series and the University Radio Guild both had made it clear that this program was to present the university library to the state.

Listeners who took the trouble to comment said they enjoyed it and that it taught them something about the university library. The educational director of the radio station said that he considered it a model program and that it represented what he thought a college or university ought to do. It combined entertainment with information in a smooth and effective manner.

A few copies of the script for this program may be obtained by writing the librarian of the University of Utah, Salt Lake City.-L. H. Kirkpatrick.

\section{University of South Carolina}

As one of the results of a staff survey of the University of South Carolina Library in the summer of 1945 , the writer ${ }^{1}$ formed a committee of himself and two staff members to take charge of publicity. The committee decided that the library should direct its efforts in three directions, each requiring different methods. Posters, exhibits, and items in the student paper would reach the students. The weekly book list and semimonthly social affairs for the various departments, with an off-campus speaker to give them point, would help form closer relations with the faculty. Publicity to the general public, and incidentally to the university administration, required a medium calling attention to the library without advertising specific services. The committee decided upon a series of art exhibits, with stories about them in the Sunday paper, for one of the devices to accomplish their aim. Another device was a series of radio programs.

1 The writer was formerly librarian of the University of South Carolina.
The first season of the university library program began on September 22 and ended thirty-seven weeks later, on June 1 . The time was Saturday evening, $7: 00-7: 15$, the station, WCOS, the local affiliate of the American. Broadcasting Co. While the other two stations in Columbia also offered free time for the program, WCOS was chosen because it could schedule the broadcasts at the most convenient and favorable hour. The programs were designed to publicize the university, the university library, and libraries in general, by talks on subjects of current or enduring interest. The speakers usually mentioned one or two books or magazine articles, incidentally. The announcer's introduction and conclusion supplied the "commercial" by mentioning the name of the library.

The programs were all talks or interviews, but the subjects varied considerably. Members of the university faculty talked about some aspect of their subject, the history of the university, special resources or 